\title{
RESPUESTA A LA CRISIS DEL ZIKA EN NICARAGUA: ANÁLISIS CRÍTICO FEMINISTA
}

\author{
THE RESPONSE TO THE ZIKA CRISIS IN NICARAGUA: \\ CRITICAL FEMINIST ANALYSIS
}

María Augusta Rodrigues Ribeiro

Recibido: 04/03/2019 - Aceptado: 22/07/2019

\begin{abstract}
Resumen
La transversalización del enfoque de género se incorpora al marco legal nicaragüense en el 2008. En correspondencia, el Gobierno nicaragüense ha promovido una estrategia de comunicación social articulada con el derecho a una vida sin violencia. Este artículo analiza la implementación de estas medidas con ocasión de la epidemia del zika desarrollando un análisis crítico feminista de los discursos del Gobierno y medios de comunicación privados durante el año 2016. Se concluye que ambos actores fortalecieron la estructura patriarcal de las relaciones sociales al reforzar los mandatos de género, obviar la responsabilidad del sector privado y obstaculizar el acceso a información clave para el ejercicio de derechos sexuales y reproductivos, lo cual afectó al logro de los objetivos de prevención del zika y de la violencia de género.

Palabras clave: políticas de salud, transversalización del enfoque de género, derechos sexuales reproductivos, medios de comunicación, relaciones de poder.
\end{abstract}

\begin{abstract}
The gender mainstreaming was incorporated into the Nicaraguan legal framework in 2008. Accordingly, the Nicaraguan Government has promoted a social communication strategy based on the right to a life without violence. This article analyzes the implementation of these measures during the Zika epidemic, carrying out a critical feminist analysis of government and private media discourses in 2016. The analysis concludes that both actors strengthened the patriarchal structure of social relations by reinforcing gender mandates, obviating the responsibility of the private sector in prevention and hindering access to key information for the exercise of sexual and reproductive rights, which would have affected the performance of prevention policies on gender violence and Zika.
\end{abstract}

Keywords: health policies, gender mainstreaming, reproductive sexual rights, media, power relations. 


\section{Introducción}

El combate a la violencia de género se ha convertido en un objetivo prioritario para la agenda pública de los países latinoamericanos y caribeños, entre ellos Nicaragua (Comisión Económica para América Latina y el Caribe; Gobierno de Reconciliación y Unidad Nacional). Sin embargo, uno de los espacios de propagación de las violencias del género son, de hecho, las propias políticas públicas. Gestadas a través del juego en la arena política, las políticas públicas nunca son neutras al género -así como tampoco lo son a la clase social o la raza-, por lo cual la distribución de poder que opera a través de ellas tiene la capacidad de reproducir o combatir la violencia de género a nivel estructural y cultural. Por ello, la integración transversal del enfoque de género en las políticas públicas aparece como una condición necesaria para erradicar la violencia de género.

Este potencial para subvertir o reproducir el orden social de género y las violencias que lo sostienen es especialmente relevante en el área de salud: las percepciones sobre lo que es propio o "natural" de cada sexo y los sesgos de género presentes en las políticas de salud dan lugar a problemáticas de gran repercusión aunque no siempre bien posicionadas en la agenda pública. Dentro de estas problemáticas destacan, en el caso de las mujeres, las relacionadas con su salud sexual y reproductiva, por estar esta vinculada a la reproducción social y biológica de la población y, por tanto, a la permanencia o transformación de las instituciones patriarcales. En Nicaragua, el aborto terapéutico ocupa un lugar prominente dentro de estas problemáticas.

También en los cuidados, la transversalización del enfoque de género aparece como una condición fundamental para lograr la igualdad sexual en el cuidado y a nivel económico, político y social. En ese sentido, los estudios de género son concluyentes en señalar que las diferencias biológicas no determinan las desigualdades de género, sino que estas son explicadas por factores sociales, políticos y económicos que han fluctuado a lo largo de la historia y que han producido un régimen caracterizado por un reparto desigual e injusto de las responsabilidades y derechos en los cuidados, definidos por Tronto y Fisher como:

Una actividad característica de la especie humana que incluye todo lo que podemos hacer para mantener, continuar y reparar nuestro "mundo" de tal modo que podamos vivir lo mejor posible. Este mundo incluye nuestros cuerpos, nuestras individualidades y nuestro entorno, que intentamos mantener en una red compleja que sostiene la vida" (citado en Martín-Palomo 62).

A partir del 2015, se integra dentro de este marco la infección por el virus del Zika al producir trastornos neurológicos y malformaciones congénitas; entre estos destacan el síndrome de Guillain-Barré en las personas adultas y la microcefalia en las criaturas no nacidas infectadas durante el primer trimestre de gestación. La transmisión 
del virus tiene lugar por vía sexual, por vía vertical o maternofetal durante el embarazo, por transmisión sanguínea y a través de la picadura de un mosquito infectado. Su principal vector es el Aedes aegypti, endémico en Centroamérica.

En respuesta a este riesgo nace en el año 2015 la política de prevención de la infección por el virus del Zika, la cual se integra en Centroamérica con la política de prevención del dengue, el chikungunya o la fiebre amarilla, por estar todas asociadas al mismo vector. En este contexto, en el presente artículo ${ }^{1,2}$ propongo analizar en qué medida se transversalizó el enfoque de género en el abordaje comunicacional de la crisis del zika en Nicaragua, con el fin de valorar la adopción de medidas género-transformativas en la comunicación social de los actores públicos y privados, tal como prevé el artículo 27 de la Ley 648 de Igualdad de Derechos y Oportunidades, en su apartado primero. ${ }^{3}$ Como veremos, si bien las políticas explícitas abogan por la igualdad de género en el país, las estructuras cognitivas y las relaciones de poder que subyacen en algunos de los discursos más penetrantes de la sociedad nicaragüense refuerzan la desigualdad. El análisis muestra como este factor limitó la eficacia de las medidas desplegadas para la prevención de la violencia de género y de la infección por zika.

\section{Antecedentes}

\section{Sobre cuidados, desigualdades y salud}

Contrariamente a las posiciones esencialistas y diferencialistas, la historia de los cuidados es clara en señalar el origen común del capitalismo liberal y el actual orden de los cuidados, de cuya desigualdad se sirvió para originar y alimentar la acumulación del capital que lo posibilitó. Varias autoras establecen claramente dicha vinculación, la cual precisó de un nuevo orden moral para su sostenimiento y estabilización (Carrasco et al.; Federici). Se produjo así un cambio radical en el modelo de división sexual del trabajo y las identidades de género, desarrollándose en Europa, entre el siglo XVII y el siglo XVIII, el mito de la maternidad hegemónica presa del instinto biológico y el del hombre hongo -en palabras del filósofo inglés Thomas Hobbes- que surge de la tierra y mágicamente alcanza plena madurez libre de ataduras personales (Carrasco et al.; Federici; Hobbes, citado en Pateman; Pérez Orozco).

Con el desarrollo del capitalismo mundial, el colonialismo y la globalización, la adopción de este nuevo contrato sexual -junto con su par, el contrato social- se extendió por todo Occidente, pero no de manera homogénea, pues a la par de la diferencia sexual, en la Modernidad se construyeron otras diferencias generadoras de alteridades, necesarias para sostener el mito del hombre blanco, autónomo, letrado y propietario (Narotzky; Pérez Orozco; Castro-Gómez). En los regímenes del cuidado latinoamericanos, la otredad fue encarnada por "las mujeres indígenas, negras, mestizas y todas aquellas que han sido subalternizadas por ser consideradas no blancas" 
(Quiroga 173). Esto generó particularidades en la región, entre las que destaca la contratación del servicio doméstico como la forma más importante de empleo femenino. A su vez, ello condujo a la construcción de significados distintos para los cuidados en las sociedades latinoamericanas, asidos al servicio doméstico y a las relaciones de servidumbre que operaron en el mismo, desarrollando un sesgo marcadamente racial, étnico y de clase (Lerussi).

Lejos de desaparecer, estos significados siguen presentes, reproduciéndose y transformándose a través de la colonialidad del ser en el lenguaje y los discursos, marcando las experiencias de los sujetos (Lerussi; Maldonado-Torres). Pero también, a través de la colonialidad del género, donde la interseccionalidad de raza/clase/sexualidad/género es un aspecto básico en el análisis de la desigualdad y la conformación del sistema moderno-colonial de género (Lugones).

Así las cosas, si bien hablamos de un régimen de cuidados con una estructura familista y feminizada en Occidente, la desigualdad en el reparto de los cuidados no es culturalmente uniforme. En el caso de Nicaragua, la literatura destaca el papel central de la participación comunitaria, lo cual se vincula con diversos factores estructurales, entre ellos: "una dependencia muy fuerte de la solidaridad como forma de enfrentar crisis, junto con un fuerte paradigma de participación comunitaria en el cuidado, en particular entre hogares y comunidades de bajos recursos económicos"; además de las políticas del Frente Sandinista de Liberación Nacional (FSLN) (en el gobierno y en oposición) y la dependencia de los servicios públicos sociales con respecto al trabajo voluntario o comunitario (Werner et al.; Martínez Franzoni y Voorend; Martínez Franzoni et al.).

Por tanto, la familia es un pilar básico en el régimen de cuidados nicaragüense, pero también lo son las "formas de organización local (...) [conformándose un] régimen de cuidado (...) altamente dependiente del trabajo no remunerado, predominantemente femenino" (Martínez Franzoni y Voorend 158). Este régimen, asentado sobre la desigualdad de género, la naturalización de los cuidados y la fragilidad del Estado, es socialmente injusto al no repartir las responsabilidades de los cuidados entre los actores, somete a las mujeres a la sobrecarga de trabajo y refuerza los roles de género, lo cual es una barrera al acceso de las mujeres a los derechos humanos, entre ellos el derecho a la salud, el autocuidado y la igualdad económica y política, entre otros (Arenas-Monreal et al.; Martínez Franzoni y Voorend; Martínez Franzoni et al.; Molyneux, 1988).

Al mismo tiempo, la participación comunitaria es un factor fundamental para avanzar en el bienestar social en Nicaragua. En ese sentido, la integración de la red comunitaria es una estrategia básica del Modelo de Salud Familiar y Comunitario (MOSAFC), adoptado por el Ministerio de Salud de la República de Nicaragua (MINSA) en el 2008. Alineada con la Declaración de Alma Ata y la Declaración de Astana, esta estrategia permite el "abordaje sistemático e integral de la respuesta social a problemas endémicos y epidémicos", lo cual posibilita el acceso de las comunidades más alejadas 
a cuidados de calidad para la salud, ante la realidad de una red estatal que sigue siento deficiente e insuficiente (Im et al.; Naciones Unidas; Organización Panamericana de la Salud, 2017; Werner et al.). Un ejemplo paradigmático de participación comunitaria lo constituye la Estrategia de las Casas Maternas, la cual ha permitido reducir la mortalidad materna, la desnutrición infantil y la mortalidad perinatal y neonatal gracias a la participación de las parteras y otros actores comunitarios. El éxito de esta estrategia fue reconocido por las Naciones Unidas mediante la concesión del Premio América en el 2011 (Im et al.; Instituto Nacional de Información de Desarrollo de Nicaragua; Organización Panamericana de la Salud, 2011).

Por tanto, también en Nicaragua, los cuidados realizados por mujeres -en su rol familiar o comunitario- han contribuido y siguen contribuyendo de forma trascendental y protagónica al sostenimiento de la salud y la vida.

En el particular de las epidemias asociadas al vector Aedes aegypti, son varios los estudios que han analizado cómo la división sexual del trabajo ha determinado un mayor involucramiento de las mujeres en la eliminación de los criaderos de mosquitos, una actividad clave en la prevención (Mosquera et al.; Organización Panamericana de la Salud, 2016; Whiteford). Así también, los roles y estereotipos de género determinan diferentes factores de riesgo a la hora de contraer las infecciones transmitidas por el vector, interactuando el género con otros determinantes estructurales (como la clase social, la raza y la edad) y los demás determinantes sociales de salud, definidos como las circunstancias en las cuales las personas nacen, crecen, trabajan, viven y envejecen, incluyendo el conjunto más amplio de fuerzas y sistemas que influyen sobre las condiciones de la vida cotidiana (Arenas-Monreal et al.; Comisión sobre Determinantes Sociales de la Salud). Por tanto, en el caso del zika -al igual que para el dengue o el chikungunya-, la discriminación, la desigualdad económica y la pobreza afianzan tanto los riesgos como los impactos sobre la salud (Phelan y Gostin).

En cuanto a las políticas para la redistribución del cuidado, los avances en Latinoamérica han sido escasos, exceptuando a Uruguay, que ha emprendido una política activa para el desarrollo de un sistema nacional de cuidados donde se integran familias, comunidades, mercado y Estado (Marco Navarro y Nieves Rico). Esta política, inspirada en el modelo social care de Daly y Lewis, enfrenta condicionantes específicos en la región latinoamericana denominados por Durán como la problemática de las tres " $\mathrm{d}$ " o "tres desafíos": la desconfianza (por la ineficacia o corrupción), la diversidad (heterogeneidad de sistemas administrativos entre zonas rurales y urbanas, orientación ideológica, etc.) y la desigualdad (de clase, etnia, género, status ciudadano, etc.). En Nicaragua, estos desafíos siguen plenamente vigentes (Martínez Franzoni y Voorend). Entre estos destacan el divisionismo político y la sacralidad de los intereses de la oligarquía local -característicos del Estado nicaragüense (Pérez Baltodano)-, los que permanecen como dos grandes rémoras al desarrollo de un sistema de bienestar social incluyente y suficiente. 


\section{La comunicación en las políticas públicas: el giro pragmático}

A finales de los años 60, Peter Berger y Tomas Luckmann sentaron las bases para estudiar la realidad como una construcción social, producto de la interacción entre actores públicos y privados con distinto posicionamiento en la arena política. Dentro de esta construcción social, las políticas públicas son explicadas como construcciones teóricas producto de un "modelo causal" o "teoría del cambio social", donde los actores perfilan conjuntamente -aunque en distinto grado- hipótesis causales y de intervención. En estas la "imputación de responsabilidades" no es una decisión neutral, sino que se ve afectada por juicios de valor. Así, el problema es definido desde un cierto marco de entendimiento (frame) en el que es percibido en un tiempo y lugar específicos (Subirats Humet et al.).

En este marco, la mediatización y la "acción corporativista silenciosa" (Subirats Humet et al. 139) ${ }^{4}$ permiten a los actores mejor posicionados afectar la definición de la hipótesis causal, manipulando la designación de los grupos objetivos y los beneficiarios finales, "esfumando" sus responsabilidades y desviando costos. Es lo que la teoría del framing entiende como encuadre: una manera determinada de enfocar los acontecimientos sociales, en la que los medios deciden qué aspectos son más relevantes, les asignan una interpretación causal y un juicio moral y expresan sus expectativas frente al devenir de las políticas (Entman, citado en Humanes).

Para el pragmatismo, la importancia de la comunicación -entendida en su sentido más amplio- va todavía más allá: Dewey comprendió su trascendencia para la construcción de los problemas públicos y, en general, para la existencia misma de los colectivos sociales, de la sociedad misma: "aprender a ser humano es desarrollar mediante la reciprocidad de la comunicación el sentido real de ser un miembro individualmente distintivo de una comunidad" (Del Castillo 11). Una sociedad en la que las consecuencias de las interacciones entre los individuos y sus actividades sean conocidas plenamente, es para Dewey la condición posibilitadora de la democracia popular. Así, la comunicación se torna esencial para la constitución de una opinión pública, al posibilitar la interpretación y valoración de las consecuencias de la acción colectiva (Redondo). Por tanto, para el pragmatismo, los medios de comunicación tienen una gran responsabilidad en la construcción de los problemas públicos y la calidad de la democracia.

En el análisis, el pragmatismo no se enfoca en las fuerzas macro o en las coerciones a los actores, sino en las operaciones cognitivas y discursivas micro, jugando el poder un papel central: "en una política pública siempre está en juego el poder (...) [en ella, cualquier] cambio es portador de una posibilidad de redistribución de recursos que puede generar consecuencias en términos de poder" (Dewey, 2004, 148-149). Por ello, Boltanski propone "una sociología de la crítica más micro que se interesa primeramente en como los individuos construyen, en sus prácticas de los discursos críticos 
y de justificación, los acuerdos y desacuerdos principales que hacen posible las cooperaciones y los conflictos" (Boltanski, citado en Zittoun 16).

En la actualidad, los medios de comunicación -cada vez más insertos en redes de capital transnacionales- muestran una habilidad creciente para el control y la manipulación de masas. Así lo señala una investigación de amplio alcance realizada por el Programa de las Naciones Unidas para el Desarrollo (PNUD) en el 2004, donde los líderes políticos latinoamericanos identificaron los medios de comunicación como el segundo actor con mayor poder político en Latinoamérica después de los grupos económicos y el sector financiero, quienes a su vez controlan el capital de los primeros cada vez más.

En Nicaragua, destacan en prensa los diarios La Prensa (LP) y El Nuevo Diario (END) -ambos fundados por la familia Chamorro en los años veinte y ochenta del siglo XX, respectivamente-, consultados en el espacio web por el $68.2 \%$ y el $55.5 \%$ de las personas con acceso a internet (CuarteroAgurcia). ${ }^{5}$ Por ello, el análisis de la producción mediática de LP y END reviste gran interés para el análisis de las políticas públicas nicaragüenses, el que no puede obviar su oposición al Gobierno sandinista y al FSLN, ni la hegemonía política e ideológica de la familia Chamorro en la sociedad nicaragüense: son los Chamorro una acaudalada "familia de notables [que] ha suministrado cinco presidentes de la República" y cuya "persistencia en el poder [constituye] un caso típico de la continuidad histórica de las oligarquías centroamericanas" ("Familia Chamorro"; Casaús Arzú).

Tras los grupos económicos y financieros, y los medios de comunicación, emerge el Poder Ejecutivo como tercer actor con mayor poder político (Programa de las Naciones Unidas para el Desarrollo). En Nicaragua este es liderado por el FSLN, que declara su compromiso con la igualdad de derechos rechazando la discriminación de clase, género y raza (Frente Estudiantil Revolucionario). El Gobierno de Reconciliación y Unidad Nacional (GRUN) asume formalmente estos principios en su modelo de gobierno, definiendo como prioridades estratégicas la equidad social y de género. Mientras los indicadores referidos a la pobreza han mostrado una evolución positiva -al reducirse del $48.3 \%$ al $24.9 \%$ de la población en el periodo 2005-2016, según cifras del GRUN, y del $48 \%$ al $30 \%$ en el periodo 2005-2014, según cifras del Banco Mundial-, los avances en igualdad de género que reflejan los indicadores internacionales ${ }^{6}$ han sido objeto de controversia (Blandón; Im et al.; Instituto Nacional de Información de Desarrollo de Nicaragua; Vidaurre Arias).

\section{Enfrentando la violencia de género a través del gender mainstreaming}

El rechazo social que produce la violencia de género ha dado pie a una larga trayectoria de investigaciones que convergen en señalarla como un elemento de sostén y reproducción de la desigualdad en el ejercicio del poder. En este marco teórico, 
la estrategia principal para combatir la violencia de género fija la igualdad de género como objetivo prioritario, transformando las condiciones socioculturales que sustentan esta violencia, esto es, los estereotipos, roles, expectativas e identidades que definen al género.

Por tanto, más allá de las medidas para el abordaje de la violencia directa, es necesario transformar los estereotipos y roles de género presentes en el conjunto de las instituciones y modificar las condiciones estructurales de acceso a los recursos. Esta es la estrategia de transversalización del enfoque de género o gender mainstreaming, según la cual es condición fundamental para combatir la violencia de género integrar la dimensión política de las políticas públicas. Es decir, desarrollar su potencial transformador con respecto al reparto del poder en relación al género (García Prince).

Dentro del marco legal nicaragüense, el principio de igualdad es protegido por el artículo 27 de la Constitución Política de 1987, donde se establece que todas las personas son iguales ante la ley y tienen derecho a igual protección sin discriminación por motivo de sexo, posición económica o credo político, entre otras. Más expresamente, el artículo 48 establece la "igualdad absoluta entre el hombre y la mujer", reafirmando la responsabilidad del Estado en la eliminación de las barreras que coartan el derecho a la igualdad y a la participación efectiva de las mujeres en la vida política, económica y social del país.

Para desarrollar este articulado constitucional, se aprueba en el 2008 la Ley 648, "Ley de Igualdad de Derechos y Oportunidades", cuyo objeto es promover la igualdad y equidad en el goce de los derechos humanos entre mujeres y hombres desde la administración pública y demás poderes del Estado (art. 1). Este texto legal -clave en el marco normativo nicaragüense- norma en su artículo 27 la integración del enfoque de género en la comunicación social, orientando a los medios a promover la igualdad de género y a evitar mensajes discriminatorios o donde se reproduzcan roles y estereotipos tradicionales. ${ }^{7}$

Esta norma se instrumentaliza a través de la Política de Estado para el Fortalecimiento de la Familia Nicaragüense y Prevención de la Violencia (PEFFPV), publicada por el GRUN en el 2014 a través del Decreto N. ${ }^{\circ} 43$. Esta apunta a la eliminación de conductas estereotipadas, mensajes violentos, discriminatorios, sexistas y excluyentes en la comunicación social. Sin embargo, no hace referencia alguna a los roles de género ni integra medidas género-transformativas. Por ello, desde una perspectiva crítico feminista, la PEFFPV se revela como un instrumento insuficiente para prevenir la violencia de género: promover una "educación para la promoción de relaciones igualitarias entre hombres y mujeres" no implica necesariamente educar en la transformación de los roles de género o en la corresponsabilidad de género en el cuidado.

En relación al sector privado, la PEFFPV establece la creación de una alianza de medios y la elaboración conjunta de una estrategia de producción de contenidos, estimulando la participación de los medios en acciones que eliminen conductas 
estereotipadas. ${ }^{8}$ Sin embargo, la implementación de este tipo de medidas afronta barreras políticas significativas, pues el país se ve afectado por una importante fractura social y política que hunde sus raíces en la guerra civil de los ochenta y que Pérez Baltodano sitúa en la misma independencia del país, en 1821. Tras el estallido de violencia producido entre abril y julio del 2018, donde fueron asesinadas 254 personas -bajo formas extremas de tortura en múltiples casos, lo que revela el nivel de odio y polarización alcanzado-, la fractura social y política se ha extremado. Este factor seguirá enturbiando las políticas públicas del país a largo plazo (Comisión de la Verdad, Justicia y Paz; Pérez Baltodano).

En cuanto a los derechos sexuales y reproductivos (DSR), el alcance de la Ley 648 es limitado: establece solamente la obligación por parte del Estado de implementar educación sexual y reproductiva "en el marco del respeto a la dignidad humana" y brindar servicios integrales de salud sexual y reproductiva (arts. 25.1, 23.8 y 25.2). Al respecto, el análisis de las políticas para la sexualidad y la reproducción indica que no hay un correlato entre los logros en igualdad de género en las esferas económica y política ${ }^{9}$ y algunas de las políticas ligadas al ámbito de los DSR. En ese sentido, es paradigmática la prohibición al aborto terapéutico, aprobada por todos los diputados de la Asamblea Nacional durante los últimos meses de la presidencia de Enrique Bolaños (Comunicación e Información de la Mujer; Im et al.).

El análisis extenso de estas políticas permite observar que los déficits en DSR han estado presentes en todos los Gobiernos formados tras el triunfo de la Revolución Popular Sandinista, en 1979 (Pizarro; Martínez Franzoni y Voorend; Largaespada Fredersdorff; Granelli). En el caso particular del aborto terapéutico, si bien esta figura estuvo contemplada dentro del código penal hasta el 2006, el acceso al derecho siempre fue sumamente precario, tal como ilustra el conocido caso de Rosita, que trascendió a la prensa internacional en 2003: una niña violada a los 9 años, a la que el MINSA negó el acceso al aborto terapéutico (Blanco; Pizarro). En el periodo 1990-2002, el Gobierno nicaragüense llegaría a aplicar una política de criminalización y persecución policial contra personas involucradas en abortos clandestinos, lo cual tuvo impactos declarados sobre la razón de mortalidad materna del país (Mann; Pizarro).

La literatura coincide en señalar que uno de los factores que están limitando el acceso a estos DSR en Latinoamérica es la segmentación de los derechos humanos en espacios naturalizados bajo el dominio de lo "público" y lo "privado", heredada de la episteme colonial y moderna de la que surge la concepción de "ciudadanía" (Molyneux, 1985). No se le escaparía a Dewey detenerse sobre esta dicotomía, falsa y estéril, estructurante de la realidad y los problemas sociales, defendiendo que "lo privado nunca puede ser exclusivamente privado, porque [...] toda interacción siempre tiene repercusiones públicas" (Redondo 25). Por ello, en la sociología pragmática se entiende que no existen tales espacios, públicos y privados, sino un continuum (Nardacchione y Hemilse Acevedo). 


\section{Metodología}

\section{Hipótesis preliminar y objetivo de investigación}

Esta investigación surge de la observación no sistemática de los discursos mediáticos producidos en 2016 en Nicaragua con ocasión de la crisis del zika, proceso que me llevó a plantear como hipótesis preliminar la presencia generalizada de un enfoque de género negativo en la arena política del país (García Prince). Para verificar esta hipótesis, en la presente investigación fijé como objetivo analizar los discursos desarrollados en 2016 en Nicaragua con ocasión de la crisis del zika en el ámbito de la comunicación social, valorando sus impactos sobre la igualdad de género, la prevención de la violencia de género y la prevención de la infección por zika.

Para ello, asumo una posición hermenéutica y parto desde una perspectiva crítico feminista, la cual se caracteriza por:

(1) perseguir la transformación efectiva de las condiciones de sumisión femenina, (2) entender la violencia de género como un instrumento para sostener la desigualdad socio-sexual y (3) no esencializar la feminidad ni la masculinidad, es decir, entender las identidades femeninas y masculinas como construcciones sociales alineadas con el orden sexual desigualitario que las configura, y no como un resultado natural (Posada Kubissa 66).

\section{Enfoque metodológico y estrategia}

Siguiendo a Van Dijk -una de las figuras exponentes en el análisis crítico del discurso (ACD) - son tres los componentes a analizar en el discurso: la estructura discursiva y semiótica, la estructura cognitiva y las macroestructuras políticas y sociales (re)producidas o (des)contruidas a través del discurso. En esta perspectiva analítica, el abuso del poder y la desigualdad social son el eje del análisis fundamental (Van Dijk).

En el ACD, el sexismo, el racismo o el clasismo son ideologías socialmente compartidas e integradas en la estructura cognitiva, los cuales generan modelos mentales sesgados con potencial para afectar la construcción social del género, la raza y la clase. Si controlan los discursos, estas ideologías alteran las condiciones de acceso a los recursos e interaccionan con las políticas públicas (Lazar). En lo que se refiere al género, estos sesgos están vinculados al androcentrismo, la insensibilidad a las diferencias de género y la aplicación de dobles estándares. En cuanto a los análisis críticos feministas del discurso, la interseccionalidad del género con otras categorías sociales, como la clase social o la raza, aparece como un aspecto básico del análisis (Lazar). 
Tomando estas premisas teóricas en consideración, acoté el análisis a los productos comunicacionales elaborados por las instituciones de gobierno y por los principales medios de comunicación en prensa web y escrita del país, dada su representatividad de los grupos de poder nacionales y por presentar entre ellos una posición política confrontativa.

La muestra a analizar fue seleccionada a partir de cuatro criterios: en primer lugar, la fecha de publicación, que quedó comprendida entre el 14 de marzo y el 2 de septiembre del 2016; en segundo lugar, la temática de los textos, que se centró en la epidemia del zika; y, por último, la fuente y la vía de publicación, acotando los textos a los publicados en el espacio web por el GRUN y por los medios de prensa de mayor alcance en el espacio web en Nicaragua: END y LP. ${ }^{10}$

La interdisciplinariedad metodológica que caracteriza los estudios críticos del discurso permite la puesta en uso de diversas técnicas de análisis. En esta investigación son utilizadas tanto el análisis textual, intertextual y contextual del discurso, como el análisis del contenido. Por esta razón, aunque los ACD suelen realizarse sobre muestras pequeñas con la finalidad de alcanzar niveles significativos de detalle (Luxán Serrano y Azpiazu Carballo), la aplicación del criterio de saturación en esta investigación, junto con la extensión del tamaño muestral hasta alcanzar una peso proporcional entre los tres participantes seleccionados, determinó un tamaño muestral de treinta textos: diez producidos por END, diez por LP y diez por el Gobierno central (el MINSA mayoritariamente) (Anexo 1). Estos fueron seleccionados por estricto orden de aparición tras buscar el término "zika" dentro de los dominios gob.ni, elnuevodiario. com.ni y laprensa.com.ni.

En su análisis, los discursos fueron relacionados con los contextos sociales y comunicativos en los que se enmarcan. Posteriormente, se analizaron sus estructuras: el léxico, la sintaxis, las metáforas, las implicaciones y presuposiciones, la descripción de los actores y las identidades (Van Dijk), interpretándolos a la luz de la teoría feminista.

Paralelamente, se codificó y se categorizó la información por medio del uso del software QDA MINER LITE v1.4.6 y se estructuró de acuerdo con el ciclo de las políticas públicas. Ello dio lugar a cinco categorías macro: definición del problema púbico, diagnóstico, caracterización del grupo de intervención, objetivos y medidas y monitoreo. ${ }^{11}$ Tras finalizar este proceso, se obtuvieron 43 subcategorías (Figura 1). Para valorar la relevancia de las categorías creadas, se calculó el porcentaje del tamaño del texto dedicado a cada categoría en relación al tamaño textual total. Este indicador se calculó para la muestra en su conjunto y por cada actor, lo que permitió analizar las similitudes, coincidencias y diferencias entre los discursos de los actores seleccionados. 
Figura 1

MAPA DE CATEGORÍAS RESULTANTE DEL ANÁLISIS CUALITATIVO

Definición de problema público
-Emergencia sanitaria
-Malformaciones congénitas
-Trastornos neurológicos
-Potencial expansión

Objetos y medidas

-Medidas prevención embarazada

-Declaración Alerta

-Medidas prevención familias

-Medidas Gobierno

-Control del foco

-Medidas prevención comunidad

-Medidas Gobierno EE. UU.

-Medidas UE

-Investigación

-Medidas tratamiento niños

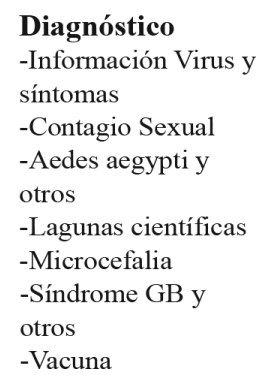

Diagnóstico

-Información Virus y

síntomas

-Contagio Sexual

-Aedes aegypti y

otros

-Lagunas científicas

-Microcefalia

-Síndrome GB y

otros

-Vacuna

Caracterización de grupos de intervención

-Familia

-Comunidad

-Mujer embarazada

-Construcción grupo riesgo

embarazada

Fuente: Elaboración propia.

\section{Resultados}

\section{Definición del problema público}

El primer hallazgo en relación con la hipótesis causal de la política señala grandes diferencias entre los actores al definir el grupo objetivo y beneficiario, lo cual revela una construcción diferente del problema público. Estas diferencias se observan, en primer lugar, en el espacio que cada actor dedicó a las mujeres embarazadas, familias, comunidades y sector privado. Así, mientras el Gobierno consideró a la familia y a la comunidad como grupos objetivo de la política, los medios de comunicación centraron la atención en la mujer embarazada, a la cual dedicaron un espacio ocho veces mayor (el $5.50 \%$ del texto producido por los medios de comunicación) que el dedicado a la familia y a la comunidad en su conjunto $(1.40 \%)$. 
Esta diferencia se observa asimismo en el tratamiento de la noticia, ya que los actores privados enfocaron la infección del zika como una problemática que afecta sobre todo a las mujeres embarazadas, en quienes depositan el riesgo:

"podemos hablar de una epidemia que se ha instalado, y el riesgo principal está en nuestras hermanas embarazadas" (Caso 18).

"si bien el riesgo para las mujeres embarazadas "es relativamente bajo, es significativo en el primer trimestre" de gestación" (Caso 24).

En el Caso 18, el cual corresponde a una noticia elaborada por el diario LP, el medio cita declaraciones de la actual vicepresidenta del país, Rosario Murillo. Sin embargo, los actores públicos no reprodujeron dicha cita, por lo cual la divergencia en el tratamiento de esta noticia ejemplifica las diferencias en el enfoque comunicacional de los actores estudiados.

Considero que este enfoque en la construcción del problema público afectó negativamente la eficacia en el control del vector implicado en la transmisión del Zika y de otros virus asociados a este mismo vector, causantes de infecciones como el dengue, el chikungunya o la fiebre amarilla. La infección por el virus del Zika es un problema de salud pública que afecta a toda la población, pues amenaza el disfrute de sus capacidades humanas. Sin embargo, son afectadas con mayor gravedad las personas que estuvieron expuestas durante la etapa de gestación. Para las criaturas no nacidas, el riesgo crece ante cada nuevo contagio, por lo que la política de prevención debe dirigirse a toda la población y no solo a las mujeres embarazadas, quienes no tienen mayores riesgos que el resto de la población adulta cuando son infectadas.

Por su parte, este énfasis de los actores privados en el binomio madre-hijo, que se observa también en el uso del término "hijos de madres infectadas durante el embarazo" (casos 22 y 25), focaliza la atención sobre las mujeres embarazadas infectadas y su conducta y les asigna una responsabilidad en el desarrollo y prevención de la infección que está mucho más vinculada con la gestión medioambiental que realizamos todos los actores conjuntamente, antes que con la capacidad de las mujeres embarazadas para evitar las infecciones asociadas al Aedes aegypti en entornos insalubres.

En síntesis, los medios de comunicación privados destacaron el binomio madrehijo y designaron a las mujeres embarazadas como el actor social afectado y como las principales responsables de evitar la transmisión del virus al feto que están gestando, obviando los determinantes sociales de salud implicados en la salud materno-infantil.

Este tratamiento de los actores privados evidencia dos sesgos que generan implicaciones negativas de cara al logro de la igualdad de género. En primer lugar, se observa una hiperrepresentación de las mujeres en su condición de embarazadas, 
enfatizando en ellas la función reproductiva. Las mujeres y las criaturas no nacidas también pueden infectarse a raíz de una relación sexual sin protección con una pareja sexual infectada. Sin embargo, estos medios nunca se refirieron a la sexualidad y a la reproducción de los hombres como un factor vinculado al desarrollo de la infección en la etapa intrauterina. Ello refiere una naturalización de la maternidad al centrar en la mujer la condición de género en su función reproductiva, aspecto que no se produce en el caso del hombre.

En segundo lugar, los medios privados depositan en estas mujeres la responsabilidad del cuidado de esa nueva vida, reafirmando y reforzando el reparto desigual de roles en el sistema sexo-género y asentando los estereotipos de género, donde el cuidado de la vida se construye como una responsabilidad feminizada.

Por otro lado, ni los actores públicos ni los privados consideraron a las empresas como actores de la política, a pesar de que la Organización Panamericana de la Salud identificó al sector privado como responsable de la implementación de medidas de prevención en la región, junto con los demás grupos objetivos: autoridades, sector público, ONG, familias y personas. Considero que esta invisibilización del sector privado como grupo objetivo de la política le permitió evadir los costos asociados a la implementación de las medidas de prevención, trasladándolos a los demás actores.

\section{Diagnóstico}

En cuanto al diagnóstico del problema público que realizaron los actores públicos y privados, hay que señalar que el contagio sexual del virus apenas recibió atención: los medios de comunicación privados hicieron referencia a esta vía de contagio solamente en tres ocasiones, dedicando un espacio equivalente al 0.10 por ciento de su producción textual a este tema; mientras que los actores públicos no hicieron ninguna referencia a este tema. En conjunto, los textos analizados apenas abordan el vínculo entre la transmisión sexual del virus y la transmisión materno-fetal: un aspecto muy relevante, ya que podría aumentar las complicaciones fetales (Sánchez). $\mathrm{Al}$ respecto, como se ha señalado anteriormente, ningún actor hizo referencia al papel de las parejas sexuales de las mujeres embarazadas en la propagación del virus y prevención de la infección.

Se aprecia en este caso un sesgo de infrarrepresentación de los hombres como copartícipes en la aplicación de medidas de prevención, lo cual relaciono con el peso de los valores patriarcales sobre la construcción de los roles de género. Considero que ello afectó negativamente la eficacia de las políticas para la igualdad de género y para la prevención de la infección por zika, pues no nombrar expresamente a los hombres como actores responsables en el control del vector y en la prevención de la transmisión sexual del virus, disminuyó el potencial de las medidas de prevención tomadas por -la mitad de- la población, al carecer estas de un principio de corresponsabilidad de género. 
Además, reafirmó los privilegios masculinos, desprendiendo a los hombres de toda responsabilidad de cara al cuidado, lo cual incluía tanto medidas de prevención de enfermedades de transmisión sexual (ETS), como labores de limpieza para la eliminación de criaderos del Aedes aegypti.

Este enfoque de género perpetuó una construcción del género típicamente patriarcal, caracterizada por la ausencia de responsabilidad masculina en el cuidado de la vida y por la patologización de los cuerpos femeninos y la responsabilidad culposa del género femenino, al enfocar injustamente el riesgo sobre las mujeres gestantes.

Por otro lado, no se encontró ninguna referencia a las desigualdades económicas y su impacto sobre la capacidad de las familias para hacer frente a las medidas de prevención y protección contra el zika.

\section{Caracterización del grupo objetivo}

Mientras los actores públicos obviaron completamente las vinculaciones entre el virus y la sexualidad humana, los actores privados abordaron este tema enfocándolo mayormente en las mujeres, a quienes dedicaron un espacio casi tres veces mayor que al hombre (1.90\% frente al $0.70 \%$ de la producción textual de estos medios). Se aprecia en ello una hiperrepresentación de la sexualidad de las mujeres, lo cual vinculo con el control que las instituciones patriarcales mantienen sobre la sexualidad femenina.

Este hallazgo se mantiene si nos enfocamos en el análisis del contenido de estas noticias, las cuales están referidas a las investigaciones realizadas en torno al virus del Zika. En estas se refiere que la presencia del virus se analizó en los hombres en varios fluidos corporales (orina, saliva y esperma), mientras que en las mujeres solo se analizó su presencia en el flujo vaginal. Es decir, en el caso del hombre se analizan varios fluidos, porque todos son relevantes, pero en el caso de la mujer solo se estudia el flujo vaginal. Se observa también en este caso un sesgo asociado a la visión androcéntrica de la salud, donde los problemas de salud se construyen desde la visión y experiencia del hombre, lo cual determina su selección como sujeto de investigación.

En cuanto al tratamiento de la sexualidad femenina que realizaron los actores privados, esta fue manifiestamente patológica. Así, en el Caso 30 puede leerse "La vagina es un 'nicho' para el Zika", lo cual reproduce la visión hegemónica de la medicina occidental sobre esta parte del aparato genital femenino: la vagina es leída en clave peyorativa y como un foco de peligro (Rodrigues y Néné).

En estos textos se refiere la verificación de la presencia del virus en el semen masculino 188 días después de la manifestación de la infección, sin aportar información sobre cuánto tiempo podría permanecer en los fluidos vaginales. Sin embargo, mientras ofrecieron datos precisos y evitaron el uso de adjetivos cuando se refirieron a la sexualidad masculina, en el caso de la sexualidad femenina los medios refirieron suposiciones sin base científica y describieron los genitales femeninos en clave patológica: 
"El virus del Zika se detectó en el esperma de un italiano seis meses después de los primeros sintomas de la infección, lo que duplica el tiempo máximo de duración registrado hasta el momento, según un estudio del instituto Spallanzani en Roma (...) El análisis detectó que, 91 días después de los primeros sintomas, el virus seguía presente en la orina, la saliva y el esperma. Al $134^{\circ}$ día, solo el esperma daba aún positivo. Y, el $188^{\circ}$ día, es decir seis meses después de los primeros sintomas, la muestra de esperma seguía dando positivo" (Caso 18).

"la vagina podría ser un lugar donde el Zika virus puede replicarse por un periodo largo. La vagina podría ser una reserva para el virus en humanos, pero hay que investigar más" (Caso 30).

Por su parte, el análisis de estos casos indica que en el momento en el cual se diseñó la muestra de análisis (septiembre del 2016), ya se había estudiado cuánto tiempo permanecía el virus en el organismo masculino, no así en el femenino, lo que nuevamente señala la presencia de sesgos de género en la investigación en salud relacionados con la visión androcéntrica característica de la civilización occidental.

Por último, en los textos producidos por los medios privados se identificó un sesgo de estereotipificación múltiple que se manifestó en el enfoque aplicado a los primeros casos de bebés nacidos con microcefalia en Nicaragua y Florida (Estados Unidos), al ser las mujeres situadas bajo categorías raciales y de clase social:

"También señaló que se están realizando otras pruebas a la paciente para descartar otras infecciones, porque resultó también positiva para virus de herpes" (Caso 16).

"El Departamento de Salud del estado de Florida (EE. UU.) confirmó este martes el primer caso de microcefalia en un bebé ligado al virus del Zika, contraído por una mujer haitiana que dio a luz en este estado. Las autoridades sanitarias señalaron que la mujer infectada, cuya identidad no fue facilitada, contrajo el virus del Zika en su país de origen, por lo que se trata de un caso importado" (Caso 15).

El medio no solo refiere que la mujer residente en Florida se infectó en el extranjero, una información que resulta relevante para valorar el riesgo de infección en la población estadounidense, sino que primeramente hace referencia a su nacionalidad haitiana, el país más pobre de Latinoamérica, un dato que por el contrario considero accesorio al principal. Con respecto al caso nicaragüense, el medio no informa solamente que la mujer se está haciendo más pruebas para verificar si la microcefalia está vinculada con la infección del zika: se filtra información personal sobre su salud señalándola como portadora del virus del herpes, violando su derecho a la privacidad y marcándola con el estigma de las ETS. 
En ambos casos, considero que este enfoque generó impactos que interfirieron negativamente en las políticas analizadas. Por un lado, supone una estereotipación de los casos de microcefalia, induciendo a la población a asociar el riesgo de contraer la infección con la pertenencia a colectivos sociales específicos: mujeres haitianas negras, empobrecidas y migrantes, o bien, mujeres nicaragüenses que practican sexualidades estigmatizadas. Considero que este enfoque resultó en una reducción del celo aplicado por la población en las medidas de prevención, además de reforzar la discriminación hacia estos colectivos.

Por otro lado, este enfoque mediático contribuyó a reforzar la construcción patriarcal de los roles de género, pues al caracterizar a las mujeres infectadas como pertenecientes a grupos sociales excluidos -negras, pobres o practicantes de sexualidades "sospechosas"-, se salvaguarda el mito de la maternidad mariana: subliminalmente, el enfoque de los medios privados transmite el ideal de la buena madre, quien no infecta a sus criaturas durante la gestación, reafirmando el mito de la "madre sacrificada y entregada a su hijo en todos los sentidos de su vida" (Romero Meza; Gómez López y Pérez Orozco).

\section{Objetivos y medidas}

El análisis de los textos sugiere que los sesgos de género presentes en la etapa de definición del problema público condujeron a diseñar paquetes de medidas insuficientes para abordar con eficacia la crisis del zika. Destaca así la ausencia de medidas destinadas al sector privado y a la prevención de la infección en poblaciones vulnerables. Como se ha señalado previamente, un abordaje eficaz del zika y demás infecciones transmitidas por el Aedes aegypti exige la corresponsabilidad de todos los actores implicados -también del sector privado, al poder infectarse las personas en su lugar de trabajo- y el abordaje de los determinantes sociales de salud implicados en el control del vector.

También destaca la ausencia de medidas de prevención contra la transmisión sexual del virus. Los medios privados de comunicación hicieron referencia a la posibilidad de contagio sexual, pero en ningún momento, ningún actor, refirió el uso de anticonceptivos de barrera durante las relaciones sexuales para hacer efectivo el ejercicio de los DSR en un contexto de alerta epidemiológica.

Con respecto al derecho al aborto, en los textos analizados tampoco se problematizó su discusión en el caso de las mujeres que sufrieron la infección durante el primer trimestre de gestación, tema que fue objeto de fuertes debates en Latinoamérica. La atención mediática sobre este tema se concentró durante el mes de febrero del 2016 - por lo que cayó fuera del periodo de estudio, establecido entre el 14 de marzo y el 2 de septiembre- a raíz de las declaraciones del Alto Comisionado para los Derechos Humanos (ACNUDH) Zeid Ra'ad Al Hussein, quien defendió el derecho al aborto seguro en Latinoamérica en el marco de la crisis del zika (Alto Comisionado para 
los Derechos Humanos). Teniendo en cuenta esta salvedad, considero que el mutismo de los actores sobre este aspecto durante los cinco meses y medio que se extendió el periodo de recogida de la muestra debe relacionarse con la preminencia de los roles y mandatos de género vinculados al patriarcado, donde la maternidad es construida como norma en la mujer.

El análisis de las medidas de prevención por actor también reveló diferencias importantes en los discursos analizados: en el caso de los actores públicos, las medidas de prevención fueron orientadas a las familias $(20.20 \%$ del texto generado por el Gobierno) y a la comunidad (15.10 \%), mientras que el espacio dedicado a las mujeres embarazadas es minoritario $(0.20 \%)$. Sin embargo, los actores privados refieren medidas de prevención orientadas principalmente a las mujeres embarazadas $(1.20 \%$ del texto generado por los medios de comunicación), seguidas de las familias (1.10 \%) y la comunidad $(0.90 \%)$.

\section{Monitoreo}

Finalmente, en relación al monitoreo de las políticas públicas se pudo identificar la presencia de prácticas de colonialidad en los textos producidos por los actores privados, los cuales enfocaron el seguimiento de la epidemia en EE. UU., obviando en gran medida su evolución en Centroamérica, a pesar de ser esta última información mucho más relevante para valorar los riesgos de contraer la infección en Nicaragua. En particular, los medios de comunicación dedicaron un $5.70 \%$ de su producción textual a informar sobre la evolución de la epidemia en EE. UU. Por el contrario, el espacio dedicado a Centroamérica fue cinco veces menor (1.20\%). Este hallazgo no se observó en el caso de los actores públicos.

\section{Discusión de los resultados}

Los resultados obtenidos del análisis contrarían la hipótesis preliminar del estudio, la cual planteaba la presencia generalizada de un enfoque de género negativo en la cobertura comunicacional de la crisis del zika. En contraste, el análisis detenido revela importantes diferencias entre los discursos analizados. Así, en relación al discurso producido por los actores públicos, los hallazgos señalan que estos textos presentaron un enfoque neutro al género: aunque presentan algunos rasgos de las políticas "género en el desarrollo" o gender mainstreaming, al no verter estereotipos de género, no persiguen un objetivo género-transformativo. A nivel práctico, ello supone una autoexclusión de los actores públicos en la construcción de los roles de género. Es decir, el enfoque neutro al género termina creando un espacio de cesión de la política de género -central para el desarrollo humano- a las fuerzas del mercado y demás actores privados. Como indico en los antecedentes, la PEFFPV no integra un objetivo género-transformativo, lo que explica este resultado. 
En cuanto a la comunicación desarrollada por profesionales y medios privados, se observa un discurso que reforzó los roles de género al señalar a las mujeres embarazadas como un grupo de riesgo de la infección por el virus del Zika y responsabilizarlas de las medidas de prevención. Así, acorde con el rol tradicional de cuidadoras, las mujeres fueron designadas por estos actores como responsables directas de la protección de las capacidades humanas de las futuras generaciones. Se observa, por tanto, que en relación a la comunicación privada no se están aplicando las medidas previstas dentro de la Ley 648: el discurso elaborado por estos medios es sexista, racista y colonialista, y promueve estereotipos de género, raza y clase, lo cual refuerza la desigualdad. En base a ello, considero que estos contenidos contribuyeron a la reedificación de una estructura de relaciones de poder desigual a lo interno de la sociedad nicaragüense. Al respecto, no se evidencia el establecimiento de la alianza de medios promovida por la PEFFPV.

También en el grado de corresponsabilidad del cuidado se observan diferencias entre los actores estudiados: mientras los actores privados conciben el cuidado como una responsabilidad privada y feminizada, para los actores públicos el cuidado constituye una responsabilidad social compartida entre familias, comunidades y Estado. Por tanto, en los actores públicos se observa la adopción de un modelo de cuidado con cierto grado de socialización, aunque parcial, pues no integra la corresponsabilidad de género ni la participación del sector privado, un aspecto -coincidente con los actores privados- indicativo del peso preponderante de los intereses del capital privado por encima del bienestar social, lo que la Comisión sobre Determinantes Sociales de la Salud de la Organización Mundial de la Salud (OMS) considera como un factor determinante de la inequidad sanitaria.

Con respecto al ejercicio efectivo de los DSR, destaca el silencio de los actores en relación a la prevención de la transmisión sexual del virus, lo que dificultó el acceso a información clave para prevenir la infección y asegurar la salud materno-infantil (Souza et al.). Además, obstaculizó el acceso al derecho a decidir si concebir o no en un contexto de alerta epidemiológica por una infección de transmisión sexual conocida. De igual manera, obvió la responsabilidad de las parejas sexuales en la prevención de la transmisión del virus a las criaturas no nacidas -las más vulnerables a la infección-, lo que supuso negar la responsabilidad masculina en el cuidado de la vida.

Por otro lado, el silencio en relación al uso de anticonceptivos de barrera debe relacionarse también con la reafirmación del mandato social de la maternidad, lo cual se advierte en la ausencia de una discusión sobre la regulación actual del aborto en Nicaragua, un tema que en ningún momento fue objeto de mención. Si bien las mujeres embarazadas no tienen mayores riesgos de salud que el resto de la población adulta cuando desarrollan la infección, los impactos socioeconómicos de la epidemia sí son decididamente más profundos para ellas: en el marco de un régimen de cuidados feminizado y en gran medida familista, serán ellas quienes asuman principalmente los 
costos económicos y emocionales que supone el cuidado de personas con trastornos vinculados a la infección del zika, lo que magnifica una vulnerabilidad económica -en las mujeres y criaturas bajo su cuidado- ya de por sí elevada en virtud de las barreras que afectan a la participación económica femenina (Daly y Lewis; Quiroga Díaz).

Sin embargo, ninguno de estos aspectos fue problematizado, lo cual sugiere que los actores dan por hecho que ellas asumirán estos costos y que las decisiones reproductivas no están en la esfera de sus derechos. Ello explicaría la ausencia de un debate sobre la regulación actual del aborto en un contexto de crisis, lo que revela el grado de naturalización de los estereotipos y roles de género y la estabilidad de las desigualdades sociales que estos generan.

En relación al conjunto de las desigualdades sociales, esta investigación señala dificultades en los actores para reconocer los determinantes sociales implicados en la crisis, lo que sugiere la posibilidad de un déficit de medidas para abordar el gradiente social de salud (Borrell y Malmusi). Si parte de las recomendaciones de la Organización Panamericana de la Salud conllevan adquirir repelentes, mosquiteros y cedazos (2016), surge la inquietud sobre la capacidad de las familias empobrecidas para asumir los costos que conlleva implementar dichas medidas, situación que estaría afectando al $18 \%$ de la población nicaragüense que vive en condiciones de pobreza y al $6.9 \%$ que vive en condiciones de pobreza extrema (Instituto Nacional de Información de Desarrollo). Sin embargo, los actores no se refirieron en ningún momento a esta problemática, ni aportaron información sobre la existencia de medidas específicas destinadas a estos sectores de la población. La posibilidad de una concentración de personas afectadas entre los grupos poblacionales más vulnerables se convertiría así en un factor generador de desigualdad social que, a largo plazo, perjudica tanto los objetivos de salud pública, como los objetivos de desarrollo del país en otras áreas de política pública (Borrell; Comisión sobre Determinantes Sociales de la Salud).

Finalmente, los resultados señalan la presencia de valores antidemocráticos en los actores privados, los cuales reprodujeron estereotipos racistas, colonialistas y sexistas en su discurso, elementos que contribuyen a la creación de subjetividades e intersubjetividades en las que las personas somos clasificadas en función de categorías sociales que determinan nuestra significación dentro del sistema-mundo. Es decir, en los términos empleados por Judith Butler, qué vidas merecen ser lloradas y qué vidas son prescindibles.

En conjunto, es previsible que los sesgos identificados hayan impactado negativamente en la lucha contra la violencia de género, al fomentar la desigualdad de género en las responsabilidades derivadas del cuidado de la vida y apuntalar la violencia cultural y estructural. Asimismo, posiblemente hayan limitado la capacidad de los actores sociales para contener la expansión del virus, cuya infección presenta secuelas a largo plazo que todavía siguen siendo estudiadas (Souza et al.). Por tanto, los hallazgos de esta investigación indican que la permanencia de la ideología de género tradicional 
en la sociedad nicaragüense limita la profundización de las políticas para el desarrollo humano, por lo que el cuestionamiento de los roles de género se convierte en una tarea ineludible dentro de la agenda social y política del país.

\section{Conclusiones}

De acuerdo con los resultados obtenidos a través del presente análisis, considero que el discurso gender mainstream desarrollado en Nicaragua con motivo de la epidemia del zika durante el 2016, reforzó los roles de género. Tanto la neutralidad de género reflejada en los contenidos producidos por los actores públicos, como el sexismo exhibido por los actores privados en su producción mediática, conduce a una reafirmación del rol tradicional de las mujeres como cuidadoras, responsables directas de la protección de las capacidades humanas.

En específico, la investigación ha permitido constatar el silencio de ambos actores en relación con el uso de métodos anticonceptivos de barrera para prevenir la infección, lo cual limita el derecho de las personas a decidir si concebir o no y cuándo. Considero que este sesgo refuerza el mandato social de la maternidad y promueve la elusión de la responsabilidad masculina en la prevención de la transmisión sexual del virus y en el cuidado de la vida en general.

Es de destacar asimismo la completa ausencia del sector privado como responsable de las medidas de protección contra la picadura del mosquito Aedes aegypti, de forma que se negó su responsabilidad en el control del vector y se toleró el traslado de los costos de la política a los demás actores.

En los discursos analizados tampoco fueron abordados los determinantes sociales implicados en el control de la infección, no refiriendo ningún tipo de medida para garantizar el acceso de las familias empobrecidas a los recursos requeridos para la implementación de las recomendaciones.

Por último, entre los discursos construidos por los actores públicos y privados, identifiqué dos diferencias importantes: por un lado, los actores privados reprodujeron estereotipos racistas, colonialistas y sexistas que no se observaron en los contenidos elaborados por los actores públicos y que generaron un sesgo por estereotipificación múltiple de las personas afectadas por la infección. En particular, en lo que se refiere al género, la investigación señala que los medios privados depositaron el riesgo en las mujeres embarazadas, patologizaron el cuerpo y la sexualidad de las mujeres, reflejaron una visión androcéntrica de la salud, hiperrepresentaron a las mujeres en sus funciones sexuales y reproductivas y vertieron estereotipos sexistas.

Por otro lado, los discursos señalaron diferencias importantes en relación con el modelo de cuidados concebido por los actores: mientras los medios de comunicación privados depositaron la responsabilidad de los cuidados principalmente en las mujeres embarazadas -seguidas por las familias y las comunidades-, los actores públicos 
enfocaron las medidas de prevención en las familias y comunidades, de manera que resultó anecdótico el espacio dedicado a las mujeres gestantes. Considero que ello refiere una concepción más social del modelo de cuidados en los actores públicos, aunque parcial, al no integrar el eje de género ni al sector privado.

En conjunto, los sesgos identificados impactaron negativamente en la lucha contra la violencia de género al reforzar los estereotipos y roles de género tradicionales, lo cual fortaleció el sistema sexo-género. Es decir, al apuntalar la violencia cultural y estructural bajo las que se sostiene la violencia de género. Asimismo, los discursos analizados redujeron la capacidad de todos los actores sociales para apercibirse responsables de la prevención de la infección, lo que sugiere la conformación de una política pública de eficacia insuficiente para el control del vector y la contención de la expansión del virus.

\section{Notas}

1 Un avance de este estudio fue presentado en el II Congreso Nacional de Ciencias Políticas, celebrado en Managua el 29 y el 30 de septiembre del 2016, en la Universidad Nacional Autónoma de Nicaragua.

2 En la elaboración de este trabajo he contado con la revisión de colegas, especialistas y legos en estudios de género. A todas estas personas quiero transmitirles mi agradecimiento por los aportes realizados, los cuales han permitido mejorar sustancialmente la versión original del artículo.

El artículo 27 de la Ley 648, dispone en su primer apartado lo siguiente: "los medios de comunicación social, agencias de publicidad, así como los comunicadores y comunicadoras, procurarán una labor social de promoción de la igualdad de derechos entre mujeres y hombres, evitando la proyección de imágenes, mensajes, información, noticias, lenguaje, entre otros, que discriminen o reproduzcan roles y estereotipos de subordinación o desventajas de las mujeres con respecto a los hombres".

Término bajo el que Subirats Humet et al. describen la situación donde "ciertas administraciones y autoridades políticas mantienen relaciones de «clientelismo» con diversos actores privados o paraestatales".

De acuerdo con los datos publicados por CuaerteroArgucia para el 2017, la prensa web nicaragüense presentaría una situación de oligopolio, en ese sentido, dos editoriales ocupan este segmento de mercado en la industria cultural: la Editorial Nuevo Amanecer (El Nuevo Diario, Diario Metro y $Q^{\prime}$ ) y la Editorial La Prensa (La Prensa y Hoy). Fuera de estos grupos, "otros medios" serían consultados por un $15.5 \%$ de internautas, sin aportar el estudio mayor detalle sobre los estos.

Estos son el índice de desigualdad de género del PNUD, que indica una reducción del $16 \%$ en la desigualdad de género para el periodo 2005-2017, descendiendo desde un valor de 0.542 al 0.456; y el índice de la brecha de género elaborado por el Foro Económico Mundial, que para el periodo 2006-2018 cuantifica el avance en igualdad de participación política en un $200 \%$ -aumentando el subíndice de empoderamiento político del 0.192 al 0.576 - y en un $47 \%$ el avance en participación económica; este subíndice aumenta del 0.463 al 0.679. En educación y 
salud, este índice cuantifica la brecha como prácticamente nula. El valor global del índice ha mejorado un $23 \%$ desde el 2006 hasta el 2018, creciendo desde 0.657 hasta el 0.809 .

Ver Nota 3.

En la segunda línea de acción del componente de comunicación social, la estrategia de prevención orienta el: "Diseño e implementación de una estrategia comunicacional a favor de los derechos de las mujeres a una vida libre de violencia, así como estimular la participación de los medios de comunicación en acciones que eliminen conductas estereotipadas que alienan, permiten, fomentan y toleran la violencia contra las mujeres, niñas, niños y adolescentes en todas sus modalidades".

Mientras que la línea de acción tres señala la: “Generación de alianzas con los medios de comunicación a fin de promover su participación para inhibir y eliminar la producción de contenidos que replican, exacerban y fomentan actitudes, conductas y percepciones estereotipadas de género que discriminan y subordinan a las mujeres; y logren desarrollar contenidos basados en el respeto, dignidad, igualdad y rechazo a los tipos y modalidades de violencia contra las mujeres y produzcan campañas de información, sensibilización y toma de conciencia sobre el tema".

\section{Ver Nota 6.}

Estos diarios pueden consultarse en los siguientes enlaces: https://www.elnuevodiario.com. ni/ y https://www.laprensa.com.ni/

En los textos analizados no se encontraron referencias a la evaluación de la política, ya que en el momento en el cual se realizó el estudio (septiembre del 2016), la política del zika todavía se hallaba en fase de implementación.

\section{Bibliografía}

“Familia Chamorro". Biografías y Vida. Recuperado de http://www.biografiasyvidas.com/ biografia/c/chamorro_familia.htm

Arenas-Monreal, Luz, et al. Aportes y desafíos del enfoque género en el estudio de las enfermedades transmitidas por vector. Salud Pública México 57/1(2015): 66-75.

Berger, P. L. y Thomas L. La construcción social de la realidad. 1968. Trad. Silvia Zuleta. Buenos Aires: Amorrortu, 2003.

Blanco, C. (22 de febrero de 2003). La niña nueve de nueve años violada aborta en una clínica privada de Managua. El País. Recuperado de https://elpais.com/diario/2003/02/22/ sociedad/1045868404_850215.html

Blandón, María Teresa. Relación del movimiento de mujeres y feminista con el movimiento y gobierno sandinistas de Nicaragua durante los últimos 40 años. Monograma. Revista Iberoamericana de Cultura y Pensamiento, 2.1 (2018): 97-128.

Borrell, C. y Davide M. La investigación sobre los determinantes sociales y las desigualdades en salud: evidencias para la salud en todas las políticas. Informe SESPAS 2010. Gaceta Sanitaria, 24/ 1 (2010): 101-108.

Borrell, C. Epidemiología social: la persona, la población y los determinantes sociales de la salud. Epidemiología para periodistas y comunicadores, Coord. Gonzalo Casino y Esteve Fernández. Barcelona: Cuadernos de la Fundación Dr. Antonio Esteve, 2015. 33-37. 
Carrasco, C. et al. Introducción. El trabajo de cuidados: antecedentes históricos y debates actuales. El trabajo de cuidados. Historia, Teoría y Políticas. Ed. Cristina Carrasco et al. Madrid: Los Libros de Catarata, 2011. 13-96.

Casaús Arzú, M. E. La Metamorfosis De Las Oligarquías Centroamericanas. Revista Mexicana De Sociología, 54/3 (1992): 69-114.

Castro-Gómez, S. Ciencias sociales, violencia epistémica y el problema de la "invención del otro". La colonialidad del saber: eurocentrismo y ciencias sociales. Perspectivas latinoamericanas. Ed. Edgardo Lander. Buenos Aires: CLACSO, 2000. 88-98.

Comisión de la Verdad, Justicia y Paz. Resumen ilustrado. Managua, 2019. Recuperado de https://www.cvjp.org.ni/home/informes

Comisión Económica para América Latina y el Caribe. Informe anual 2013-2014. El enfrentamiento de la violencia contra las mujeres en América Latina y el Caribe. Santiago de Chile: Naciones Unidas, 2014.

Comisión sobre Determinantes Sociales de la Salud. Subsanar las desigualdades en una generación: Alcanzar la equidad sanitaria actuando sobre los determinantes sociales de la salud. Ginebra: Organización Mundial de la Salud, 2009.

Comunicación e Información de la Mujer AC. Se penaliza en Nicaragua el aborto terapéutico, CN cimacnoticias, 27 octubre 2006. http://www.cimacnoticias.com.mx/node/56160

CuarteroAgurcia. Hábitos de los Usuarios Nicaragüenses en Internet 2017. Managua, 2017.

Daly, M. y Jane L. El concepto de "social care" y el análisis de los Estados de Bienestar contemporáneos. El trabajo de cuidados. Historia, Teoría y Políticas. Ed. Cristina Carrasco et al. Madrid: Los Libros de Catarata, 2011. 225-251.

Del Castillo, R. Érase una vez en América. La opinión pública y sus problemas. John Dewey. Madrid: Ediciones Morata, 2004. 11-55.

Dewey, J. Democracia y educación: una introducción a la filosofía de la educación. Madrid: Ediciones Morata, 1998.

Dewey, J. La opinión pública y sus problemas. Madrid: Ediciones Morata, 2004.

Durán, M. Á. Alternativas Metodológicas en la Investigación sobre el Cuidado. El trabajo de cuidados: una cuestión de derechos humanos y políticas públicas, Ed. ONU Mujeres. México: Naciones Unidas, 2018. 24-42.

Federici, S. Calibán y la bruja. Mujeres, cuerpo y acumulación originaria. Madrid: Traficantes de Sueños, 2010.

Foro Económico Mundial. The Global Gender Gap Report 2018. Ginebra. 2018.

Frente Estudiantil Revolucionario. Programa Histórico del Frente Sandinista de Liberación Nacional (FSLN). Managua: FSLN, 1972.

García Prince, E. Políticas de Igualdad, equidad, mainstreaming de género ¿De qué estamos hablando?: Marco conceptual. San Salvador: Programa de las Naciones Unidas para el Desarrollo, 2008.

Gobierno de Reconciliación y Unidad Nacional. Plan Nacional de Desarrollo Humano 2012-2016 (a seguir transformando Nicaragua). Managua, 2012.

Gómez López, M. E. y Pérez Orozco, A. Resolviendo la vida, renegociando los cuidados: Una lectura feminista de las prácticas de cuidados en Matagalpa. Las resistencias nuestras de cada día: Subversiones cotidianas a las violencias simbólicas y materiales. Ed. Ana Victoria Portocarrero y Edurne Larracoechea. Managua: UCA, 2016. 122-174.

Granelli, R. La penalización del aborto en Nicaragua. Una práctica de feminicidio de Estado (Tesis de maestría). Universidad de Granada, 2011. 
Humanes, M. L. El encuadre mediático de la realidad social. Un análisis de los contenidos informativos en televisión. Zer-Revista de Estudios de Comunicación, 6/11 (2001).

Im, F. et al. Nicaragua. Paving the way to faster growth and inclusion. Systematic Country Diagnostic. Banco Mundial, Corporación financiera internacional, 2017.

Instituto Nacional de Información de Desarrollo de Nicaragua. Reporte de Pobreza y DesigualdadEMNV 2016. Managua: INIDE, 2016.

Instituto Nacional de Información de Desarrollo y Ministerio de Salud. Encuesta Nicaragüense de Demografía y Salud ENDESA 2011/12. Informe Final. Managua: INIDE, 2014.

Largaespada Fredersdorff, C. Igualdad de género, pobreza, politicas de conciliación entre los ámbitos productivo y reproductivo. Un estudio de caso sobre Nicaragua. Managua: United Nations Fund for Population Activities, 2006.

Lazar, M. Feminist Critical Discourse Analysis: Articulating a Feminist Discourse Praxis. Critical Discourse Studies 4.2 (2007): 141-164.

Lerussi, R. Trabajo doméstico y migraciones de mujeres en Latinoamérica. El caso de las nicaragüenses en Costa Rica. Punteo para un enfoque de reflexión y acción feministas. Anuario Estudios Centroamericanos 33-34 (2008): 183-203.

Lugones, M. Colonialidad y género. Tejiendo otro modo: Feminismo, epistemología y apuestas descoloniales en Abya Yala. Ed. Yuderkys Espinosa Miñoso, et al. Popayán (Cauca): Universidad del Cauca, 2014. 57-73.

Luxán Serrano, M. y Azpiazu Carballo, J. Módulo III Metodología para la implementación la igualdad. Tema 4: Metodologías de Investigación Feminista. Emakume eta gizonen Berdintasunaren gaineko Masterra / Máster en Igualdad de Mujeres y Hombres. Donostia: Universidad del País Vasco, 2016.

Maldonado-Torres, N. Sobre la colonialidad del ser: contribuciones al desarrollo de un concepto. El giro decolonial: reflexiones para una diversidad epistémica más allá del capitalismo global. Ed. Santiago Castro-Gómez y Ramón Grosfoguel. Bogotá: Siglo del Hombre Editores, 2007. 127-167.

Mann, E. S. Familialism in Nicaragua: Reproductive and Sexual Policy Regimes, 1979-2002. Meeting ISA's Research Committee 19, Chicago, 2005.

Marco Navarro, F. y Nieves Rico, M. Cuidado y políticas públicas: debates y estado de situación a nivel regional. Las fronteras del cuidado. Agenda, derechos e infraestructura. Coord. Laura Pautassi y Carla Zibecchi. Buenos Aires: Biblos, 2013. 27-58.

Martínez Franzoni, Juliana et al. The Political Social Economy Care Nicaragua. Familialism Care Exclusionary Social Policy Regime. Ginegra: NN.UU., 2010.

Martínez Franzoni, J. y Voorend, K. Veinticinco años de cuidados en Nicaragua 1980-2005: Poco estado, poco mercado, mucho trabajo. San José: Guayacán, 2012.

Martín-Palomo, M. T. Autonomía, dependencia y vulnerabilidad en la construcción de la ciudadanía. Zerbitzuan: Revista servicios sociales, 48 (2010): 57-69.

Ministerio de Salud de la República de Nicaragua. Anexo al Presupuesto General de la República 2018. Marco Presupuestario de Mediano Plazo 2018 - 2021. Proyecto de Presupuesto General de la República 2018. Ed. MHCP. Managua: GRUN, 2018. 280-304.

Molyneux, Maxine. Mobilization without emancipation? Women's interests, the state, and revolution in Nicaragua. Feminist Studies, 11/2 (1985): 227-254.

Molyneux, Maxine. The Politics of Abortion in Nicaragua: Revolutionary Pragmatism - or Feminism in the Realm of Necessity? Feminist Review, 29 (1988): 114-132. 
Mosquera, Mario et al. Comunicación, movilización y participación: lecciones aprendidas en la prevención y control de la fiebre dengue (FD). Investigación \& Desarrollo 14/1 (2006): 120-151.

Nardacchione, G. y Hemilse Acevedo, M. Las sociologías pragmático-pragmatistas puestas a prueba en América Latina. Revista Argentina de Sociología, 9-10/17-18 (2013): 86-118.

Narotzky, S. Antropología económica. Barcelona: Melusina, 2004.

Nicaragua. Decreto No. 43-2014, del 30 de julio, por el que se publica la Política de Estado para el fortalecimiento de la familia nicaragüense y prevención de la violencia (PEFFPV). La Gaceta, núm. 142, 31 julio 2014, pp. 6269-6273.

Nicaragua. Ley No. 648 Ley de Igualdad de Derechos y Oportunidades. La Gaceta. Diario oficial, núm. 51, 12 marzo 2008, pp. 1668-1674.

Nicaragua. Texto de la Constitución Política de la Republica de Nicaragua con sus reformas incorporadas. La Gaceta. Diario oficial, núm. 32, 18 febrero, 2014, pp. 1254-1284.

Naciones Unidas. Declaración Astana. Conferencia Mundial Sobre Atención Primaria de Salud. Desde Alma-Ata hacia la cobertura sanitaria universal y los Objetivos de Desarrollo Sostenible. Astana (Kazajstán): OMS y UNICEF, 2018.

Oficina del Alto Comisionado para los Derechos Humanos. Defender los derechos de las mujeres es esencial en la respuesta al Zika-Alto Comisionado para los DD HH. ACNUDH, 5 febrero 2016. Recuperado de https://www.ohchr.org/SP/NewsEvents/Pages/DisplayNews. aspx?NewsID $=17014 \&$ LangID $=S$

Organización Panamericana de la Salud. Nicaragua galardonada con Premio América 2011 por reducción la mortalidad materna. 2011. Recuperado de https://www.paho.org/hq/ index.php?option=com_content\&view=article\&id=6011:2011-nicaragua-galardonadapremio-america-2011-reduccion-mortalidad-materna\&Itemid=135\&lang=es

Organización Panamericana de la Salud. Salud en Las Américas, edición del 2017. Resumen: panorama regional y perfiles de país. Washington, D.C.: OMS, 2017.

Organización Panamericana de la Salud. Preguntas frecuentes sobre el control de vectores del virus del Zika. 2016. Recuperado de http://www.paho.org/hq/index.php?option=com_ docman\&task=doc_view\&gid=33882\&Itemid=270\&lang=en

Pateman, Carole. 'God Hath Ordained to Man a Helper': Hobbes, Patriarchy and Conjugal Right. British Journal of Political Science 19/4 (1989): 445-463.

Pérez Baltodano, Andrés. Mi renuncia al Consejo Editorial. Confidencial. 2019. https://confidencial.com.ni/mi-renuncia-al-consejo-editorial/

Pérez Orozco, A. Subversión feminista de la economía: aportes para un debate sobre el conflicto capitalvida. Madrid: Traficantes de sueños, 2014.

Phelan, A. y Lawrence O. G. The Human Rights Dimensions of Zika. Academic impact. NN.UU. 2016. https://academicimpact.un.org/content/human-rights-dimensions-zika

Pizarro, A. M. Derechos sexuales y reproductivos. Mortalidad materna en Nicaragua. Red de Salud de las Mujeres Latinoamericanas y del Caribe (RSMLC), 2006.

Posada Kubissa, L. Otro género de violencia. Reflexiones desde la teoría feminista como teoría crítica. Asparkía: investigació feminista, 19 (2008): 57-71.

Programa de las Naciones Unidas para el Desarrollo. La democracia en América Latina: hacia una democracia de ciudadanas y ciudadanos. Ed. Fernando Esteves. Buenos Aires: Aguilar, Altea, Taurus, Alfaguara, 2004.

Programa de las Naciones Unidas para el Desarrollo. Gender Inequality Index (GII). Human Development Reports. 2018. Recuperado de http://hdr.undp.org/en/indicators/68606 
Quiroga Díaz, N. Tejiendo otro modo: Feminismo, epistemología y apuestas descoloniales en Abya Yala. Ed. Yuderkys Espinosa Miñoso et al. Popayán (Cauca): Universidad del Cauca, 2014. 161-178.

Redondo, I. The Public and its problems. Opinión pública y comunicación en la obra de John Dewey. Universidad de Navarra, 2005. Recuperado de http://www.unav.es/gep/Dewey/ OpinionPublicaComunicacion.pdf

Rodrigues, S. B. y Néné, M. “The place of episiotomy in history: A sore review." Journal of Nursing Education and Practice, 9 (2019): 122-128.

Romero Meza, M. Maternidades feministas; Experiencias y reflexiones en construcción. Las resistencias nuestras de cada dia: Subversiones cotidianas a las violencias simbólicas y materiales. Ed. Ana Victoria Portocarrero y Edurne Larracoechea, Managua: UCA, 2016. 54-89.

Sánchez, A. “Dinámica del Virus de Zika en los fluidos corporales y riesgo de transmisión sexual en una zona no endémica". Enfermedades Emergentes, 17/2 (2018): 99-100.

Souza, I. et al. Late Neurological Consequences of Zika Virus Infection: Risk Factors and Pharmaceutical Approaches. Pharmaceuticals, 12/2 (2019). DOI: 10.3390/ph12020060.

Subirats Humet, J. et al. Análisis y Gestión de Políticas públicas. Barcelona: ARIEL, 2008.

Van Dijk, T. A. Análisis crítico del discurso. Revista Austral de Ciencias Sociales, 30 (2016): 203-222.

Vidaurre Arias, A. (25 de febrero de 2019). Buena nota Nicaragua en informe Gender Gap es una burla. El Nuevo Diario. Recuperado de http://www.elnuevodiario.com.ni/ nacionales/486516-gender-gap-oea-crisis-nicaragua

Werner, D. et al. Cuestionando la solución: Las Políticas de Atención Primaria de Salud y Supervivencia Infantil. HealthWrights, 2000. http://www.healthwrights.org/content/books/CLS/ index.htm

Whiteford, L. M. The Ethnoecology Dengue Fever. Medical Anthropology Quarterley, 11/2 (1997): 202-223.

Zittoun, Ph. Hacia un enfoque pragmático de la acción pública. Mundos Plurales - Revista Latinoamericana De Políticas Y Acción Pública, 3, 1(2016): 9-32.

María Augusta Rodrigues Ribeiro. Investigadora social de origen hispanoportugués, formada como economista especializada en género, desarrollo humano y desarrollo socioeconómico. Actualmente, realiza un doctorado en el Programa de Estudios Interdisciplinares de Género de la Universidad Autónoma de Madrid (España). Ha colaborado con la Universidad Centroamericana en el campus de Managua (Nicaragua) en la docencia de análisis y evaluación de políticas públicas y de género y equidad social. Como consultora independiente, ha prestado servicios especializados en el ciclo de gestión de proyectos y programas de intervención social a instituciones del gobierno de Nicaragua, organismos de cooperación gubernamental, organizaciones del tercer sector y Organizaciones de la Sociedad Civil (OSC).

Contacto: mar.rodrigues01@predoc.uam.es

ORCID: 0000-0002-5753-4631 


\section{ANEXO 1}

\begin{tabular}{|c|c|c|c|}
\hline & Título & Fecha & Web \\
\hline 1 & $\begin{array}{l}\text { Nicaragua declara alerta epidemiológica para intensificar lucha contra } \\
\text { el dengue, chikungunya y Zika }\end{array}$ & $05 / 05$ & MINSA \\
\hline 2 & $\begin{array}{l}\text { Informan sobre forma aparentemente más benigna del virus Zika en } \\
\text { Nicaragua }\end{array}$ & $29 / 06$ & MINSA \\
\hline 3 & $\begin{array}{l}\text { MINSA reitera las medidas de prevención para evitar el dengue, } \\
\text { chikungunya, Zika y demás enfermedades que tienden a incrementarse } \\
\text { con las lluvias }\end{array}$ & $06 / 06$ & MINSA \\
\hline 4 & 6 mujeres que han tenido Zika han dado a luz bebés saludables & $25 / 07$ & MINSA \\
\hline 5 & Eliminar los criaderos de zancudos para prevenir el dengue & $14 / 03$ & MINSA \\
\hline 6 & En Nicaragua siguen naciendo bebés sanos de madres que tuvieron Zika & $04 / 08$ & MINSA \\
\hline 7 & La UE apoya la investigación sobre el virus del Zika & $10 / 06$ & CINICYT \\
\hline 8 & MINSA llama a reforzar las medidas de prevención del dengue & $25 / 07$ & MINSA \\
\hline 9 & Lucha antiepidémica se intensifica en el barrio Walter Ferreti & $18 / 07$ & MINSA \\
\hline 10 & Sigue la batalla contra el Aedes aegypti en Managua & $23 / 08$ & MINSA \\
\hline 11 & El Zika en aumento acelerado & $29 / 07$ & La Prensa \\
\hline 12 & Identifican segundo mosquito transmisor de Zika en Brasil & $21 / 07$ & La Prensa \\
\hline 13 & Más de 700 casos de Zika en el país & $28 / 07$ & La Prensa \\
\hline 14 & Pipitos vigilantes ante aumento de microcefalia por Zika & $26 / 08$ & La Prensa \\
\hline 15 & Primer caso de microcefalia ligado a Zika en Florida & $28 / 06$ & La Prensa \\
\hline 16 & Primer caso de microcefalia por Zika en Nicaragua & $09 / 08$ & La Prensa \\
\hline 17 & Virus del Zika sin pausa en el país & $04 / 08$ & La Prensa \\
\hline 18 & Virus del Zika: 1,211 casos en Nicaragua & $12 / 08$ & La Prensa \\
\hline 19 & Zika sigue siendo una emergencia & $02 / 09$ & La Prensa \\
\hline 20 & EE. UU. Alerta sobre viajes a Miami por Zika & $01 / 08$ & La Prensa \\
\hline 21 & EE. UU. Se queda sin fondos para combatir el Zika & $30 / 08$ & END \\
\hline 22 & La infección congénita del Zika puede provocar sordera en los niños & $30 / 08$ & END \\
\hline 23 & Nicaragua acumula 1661 casos de Zika & $30 / 08$ & END \\
\hline 24 & Siguen sin respuesta las dudas científicas respecto al Zika y sus efectos & $02 / 09$ & END \\
\hline 25 & Un tercio de la humanidad vive en zonas de riesgo de propagación del Zika & $01 / 09$ & END \\
\hline 26 & Así evoluciona el Zika en Nicaragua & 07/05 & END \\
\hline 27 & Casos de Zika en Nicaragua aumentan a casi 700 & $26 / 07$ & END \\
\hline 28 & Dengue y Zika atacan más en Nicaragua & $23 / 07$ & END \\
\hline 29 & El rash no es sinónimo de tener Zika & $25 / 07$ & END \\
\hline 30 & La vagina es un "nicho" para el Zika, según un estudio & $25 / 08$ & END \\
\hline
\end{tabular}

